
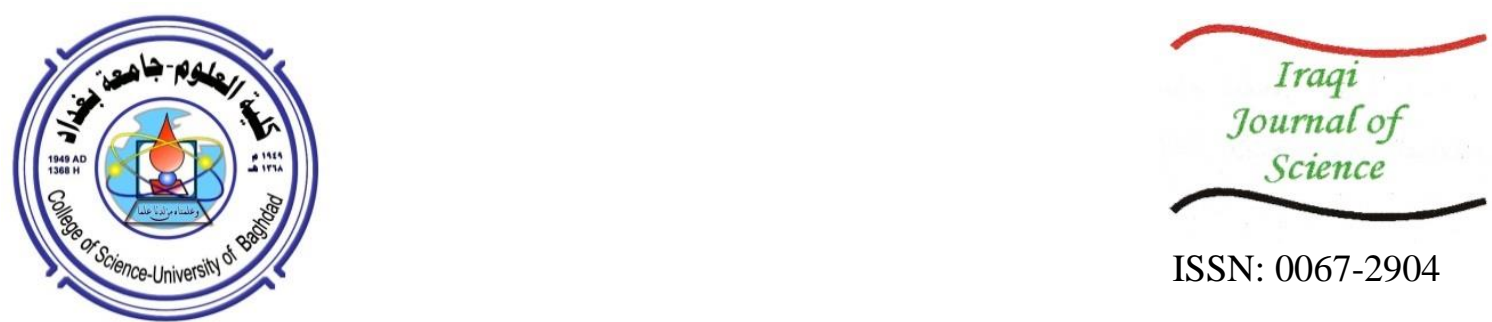

ISSN: 0067-2904

\title{
Design of a Sustainable City in Iraq Using SAM Program to Calculate Renewable Energy
}

\author{
Safaa J. Al-Swaiedi ${ }^{1}$, Amani I. Altmimi ${ }^{2}$, Aamar A. Al-khalidi ${ }^{3}$ \\ ${ }^{1}$ Department of Atmospheric Science, College of Science, Mustansiriya University, Baghdad, Iraq \\ ${ }^{2}$ College of Energy and Environmental Sciences, Al-Karkh University of Science, Baghdad, Iraq \\ ${ }^{3}$ Department of Energy Engineering, German Jordanian University, Amman, Jordan
}

Received: 10/1/2021

Accepted: 22/3/2021

\begin{abstract}
Urban design and human activity are main causes of environmental pollution and climate change, such as reliance on energy production plants, factories and transportation that depend on fossil fuels, in addition to transformation of most green areas into residential areas. This paper aims to establish a sustainable city with an environment friendly urban design that contributes to exploitation of natural resources in the generation of electric power, use of green means of transport and thus the reduction of pollution. Anah site was chosen as the best site for designing a sustainable city, with its natural resources, air quality and moderate climate. The total area of the city is $9990187 \mathrm{~m}^{2}$ divided into seven main parts, which include residential area, green areas, agricultural areas, public areas, wind farm, industrial area, and solar collecting area. SAM software has also been used in the city's renewable energy accounts. It was found that the annual output of the wind farm consisting of 15 turbines is $71080608 \mathrm{kWh}$ and the power factor ratio is $36.1 \%$. While the annual production of solar energy for each house was equal to $12527 \mathrm{kWh}$ and the power factor was $23.8 \%$.
\end{abstract}

Keywords- Anah, Public Area, Renewable energy, Sustainability, Wind farm.

\section{تصميم مدينة مستدامة في العرلق باستعمال برنامج SAM لحساب الطاقة المتجددة}
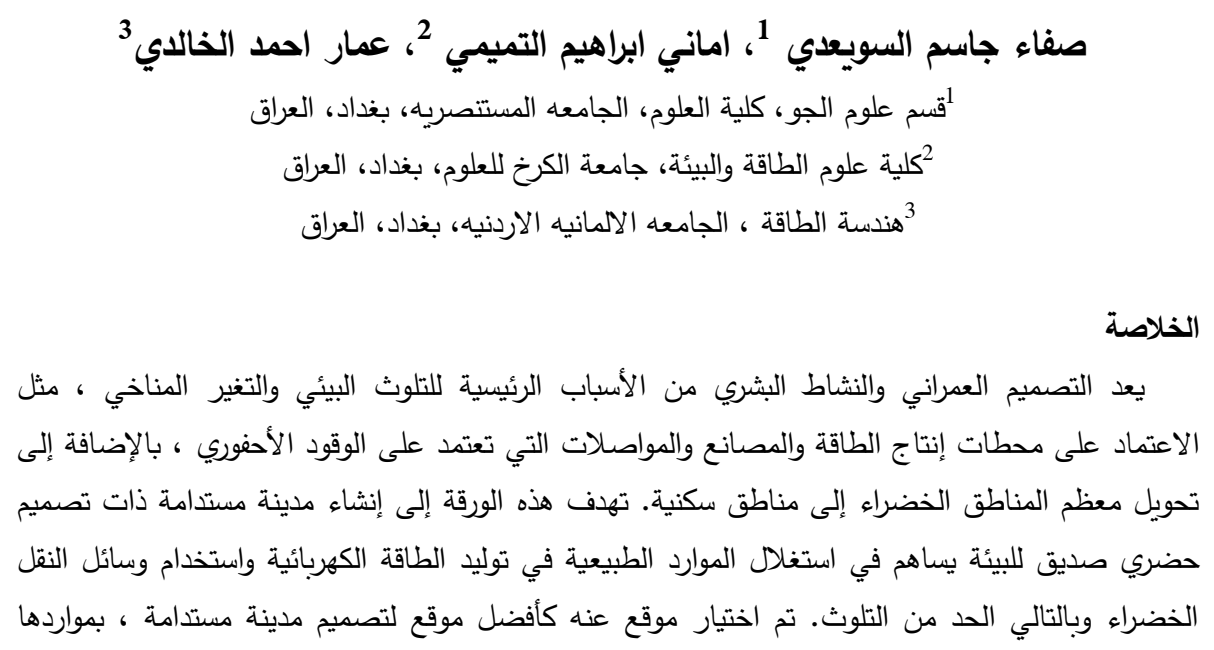

*Email: safaa.jasim1992@gmail.com 


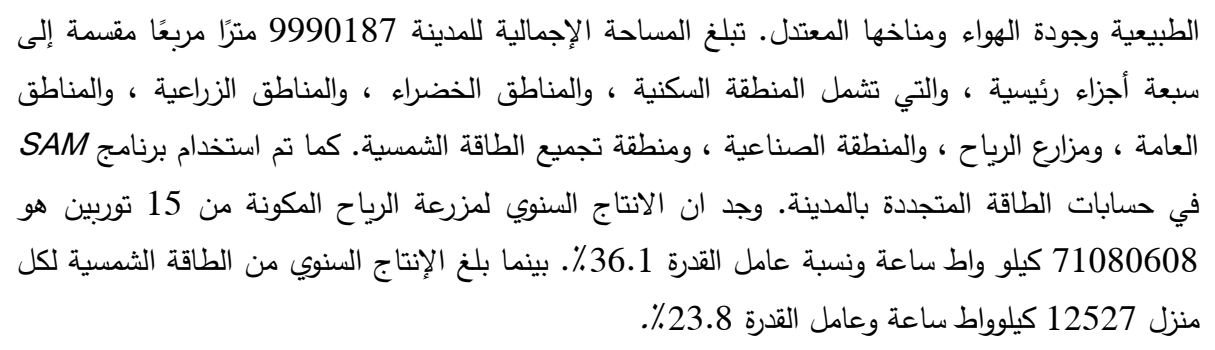

\section{Introduction}

The future of human settlements is expected to be urban. At the beginning of the twentieth century, there were only 16 cities with a population of one million or more, most of them located in the advanced industrial countries [1]. By 2010, the situation has changed and there are 449 cities with a population of 1 million or more, most of them in developing countries. In the future, these cities are expected to dominate 60 percent of the world's population by 2030 and nearly 70 percent by 2050 [2]. This urbanization is accompanied by opportunities and challenges that affect future of city's residents. The sustainable city is designed on the basis of sustainable development meeting the needs of the present without sacrificing ability of future generations to meet their own needs, in addition to taking into account its residents in reducing energy, water and food consumables, thus reducing waste, air and water pollution. In 2015 D. Brodowicz wrote a book on green urban models and the challenges facing $21^{\text {st }}$ century cities. These challenges include population growth, air pollution, congestion, energy efficiency and demand for high quality of life [3]. Macharis and Kin 2017 investigated 4A's for a sustainable city. Whereas, 4A's position was awareness, avoidance, action, transformation and anticipation of new and advanced technologies. They also provided an overview of potential concepts and the most important characteristics of each category [4]. In 2018 Ammar and et al. published a paper in which work was done to select a site and design a sustainable city in Jordan. The complexity of choosing a site arose due to the semi-arid climate along with very limited traditional energy resources. In narrowing the selection process, the authors have developed a selection criterion for a sustainable city in Jordan [5]. This paper aims to design a sustainable city based on modern technologies that maintain the standard of living for people at the present time and for future generations. The essential part of city design is site selection, so Anah city was chosen as the best suitable location for designing a sustainable city in Iraq due to the abundance of natural resources and a moderate climate, which will be discussed in detail later. AutoCAD was used to design the city's structure in a circular sector with a capacity of 30000 person. The reason for choosing the circular design of the city is due to the shape of the water wheel in the city of Anah, and from the architectural side, there are several factors, most notably the proximity of residential sectors to the center in and the transportation and the possibility of walking or using bicycles.

\section{The Concept of a Sustainable City}

Sustainable city is a city designed with environmental, social and economic impact in mind, and meets the needs of the present without affecting future generations. The goals of the sustainable city are that it is able to sustain itself by relying on the natural environment and preserving it, and the ability to provide itself with renewable energy from natural sources, most notably the sun and wind. The sustainable city also aims to reduce the required inputs from energy, water, food, waste and pollution, in order to obtain a sustainable and environment friendly future. The most important characteristics of a sustainable city are:

- Renewable energy sources that include solar, wind and biogas.

- Various agricultural plans within the city or on its borders.

- Wide green areas.

- Green Transportation.

- A sustainable sanitation system. 
- Recycling and utilizing waste for several purposes.

- Zero energy buildings.

- Strategic planning for the city.

- Increasing awareness of the city's residents through the awareness centers located in it.

\section{City Plan}

The idea that adopts the design of the city structure is to be in a form of a circular sector, and therefore the distances between the residential units will be close to the intermediaries between the green and public areas, which in turn give the city's residents a sense of wellbeing. In addition, reducing the use of transportation, which in turn reduces energy consumption. All areas of the city will include a rainwater collection system, a water distribution and storage tower, energy storage units, and civil defense departments throughout the regions. The areas of the city can be divided into seven parts:

\subsection{Green Areas}

Green areas will include a public park in nature and will have a good landscaping design to bring out the beauty of nature with water flowing in artificial rivers that also act as air cleansing and purifying elements. It would be planted with flora that include fruitful tree that would be accessible to anyone in the city and also planted with edible shrubs. The location of green areas is located between residential and public areas as well as roads, which gives street and people who pass through the city a pleasant and calm feeling of green as they pass by giving the city a beautiful entrance filled with elements from nature. Green areas are important in the city to balance out the $\mathrm{CO}_{2}$ emissions from the industries and the human factor and animal husbandry.

\subsection{Housing Areas}

Homes in this area will be distributed among farms to give the city a calm and peaceful atmosphere in which its residents will gain a more comfortable and intimate feeling towards nature. The house should have easy and close access to green areas and public places, and it should be away from the wind farm that may produce some noise. The housing department should be close to waste treatment and the industrial section as some of the people who live their work in this section. The housing sector should also be close to the available agricultural centers and a number of residents will also work there. There is a rainwater collection system distributed to the housing sector and other city sectors. This water is treated by the water treatment plant and thus ready to be used either for home use, drinking or irrigation, and also can be used in the industrial area. Some residents will work in the maintenance and control departments of the solar collectors and the wind farm. Homes will be designed in a way that can benefit from the climate, by designing vital climate architecture and passive solar architecture for residential units to achieve maximum efficiency and take advantage of the climate conditions of the region.

\subsection{Public Areas}

The public area or the "city center" would include all the facilities needed for a high standard of living. The facilities included are mentioned as follows: Schools, Universities, Research centers, mosques and churches, the central control hub, Offices for the management team that would take responsibility for organizing the cities affairs, Public libraries, Leisure center for entertainment, market place where things are traded to the outside world and things are brought in, Hospitals and medical centers, Fire department and Security zones.

\subsection{Agricultural Land}

It includes all agricultural buildings that produce food for the city, and through which the city's economy is strengthened by selling excess agricultural products to other cities. The most prominent agricultural structures are as follows: Vertical cultivation, plastic houses and aquaponics structures that produce leafy vegetables, as well as their freshwater fish ponds. 


\subsection{Waste Treatment (Industrial Zone)}

This zone will act as the heart of sustainability for the city as it will include the following structures: Wastewater treatment plant, solid waste treatment plant, up cycling workshop for reusing material, recycling center, technology center for maintenance purposes, water desalination plant and water distribution center.

\subsection{Solar Energy Collection Zone}

This area includes solar plants that power the sustainable city.

\subsection{Wind Farm Zone}

The wind farm includes turbines that are installed to power the city.

\section{System Advisor Model}

The System Advisor Model (SAM) is one of the programs for renewable energy accounts and economies, and it is one of the free programs that facilitate decision-making for people interested in energy and they are:

- Engineers and project managers

- Analysts of government

- Developers of technology

- Researchers

SAM can formulate many types of systems renewable energy:

- PV systems with large and small ranges.

- Lithium batteries and battery storage.

- Focus on solar power generation systems.

- Industrial processes.

- Wind energy includes large wind farms or individual turbines.

- Solar energy for water heating.

- Geothermal energy calculations.

- Biomass energy calculations.

- High focus PV systems.

The most important requirement of (SAM) is the weather file for weather conditions and renewable energy resources for the project site. Depending on the type of system that requires its design, the file can be chosen from a list in the program window, downloaded from the Internet, or a special file can be created from the required data in the accounts. This file requires hourly data for a full year, so a set of 8,760 values are generated for each variable contained within the file. The wind energy calculation file is in (.srw) format, which contains both wind speed and direction, temperature and pressure for more than height. While the solar energy file is in (.csv) format, which contains the following variables in order (year, month, day, hour, minute, dew point, Diffuse Horizontal Irradiance (DHI), Direct Natural Irradiance (DNI), Global Horizontal Irradiance (GHI), pressure, temperature, wind speed and direction). It can be illustrated through the following figure of the SAM program window, which includes an example for calculating the total annual and monthly energy of wind energy. 


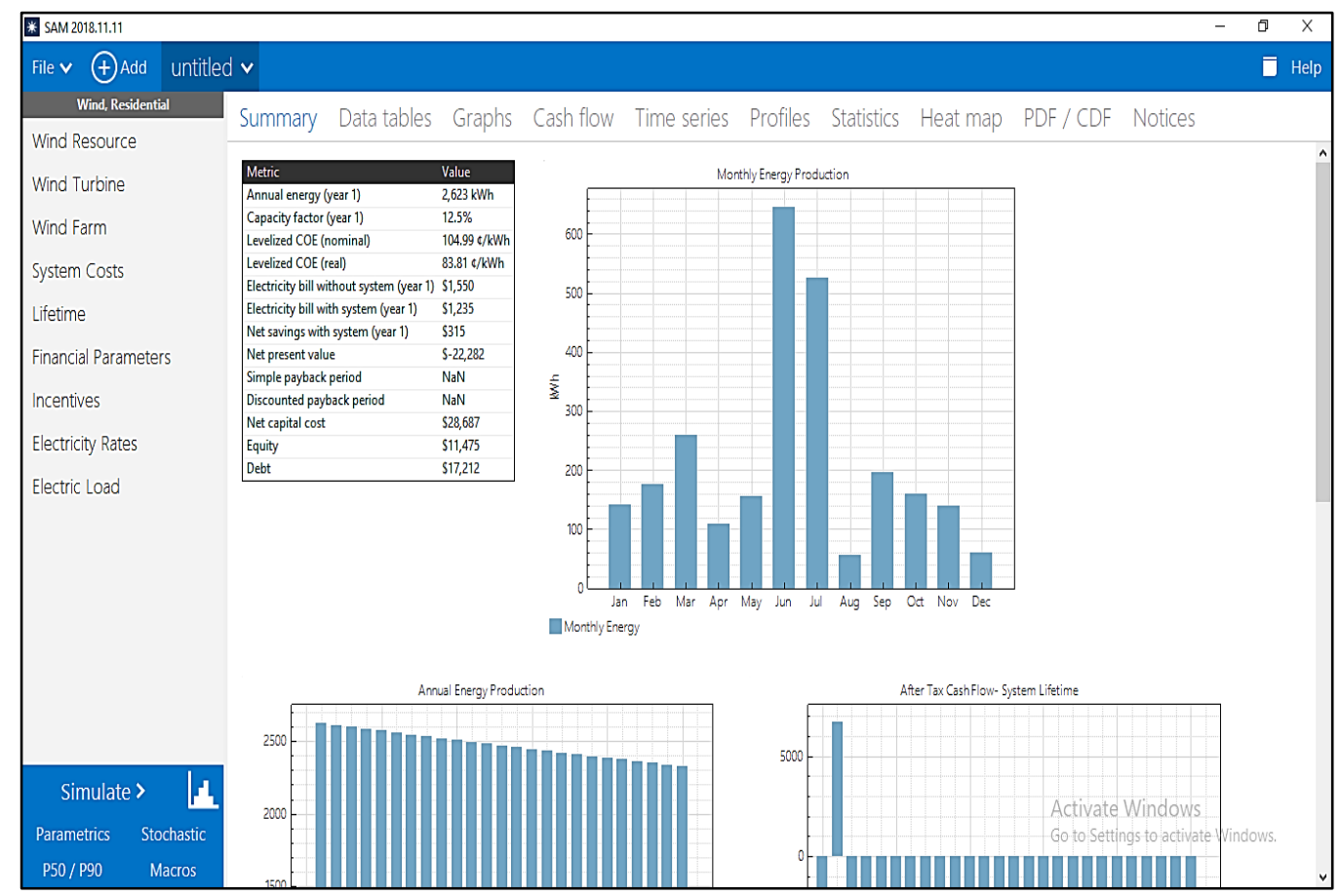

Figure 1-(SAM) calculations of total annual and monthly wind energy.

\section{Solar Energy}

Solar energy is known as heat and light from the sun, which humans have exploited since ancient times to exploit them in advanced technologies. Solar radiation, along with secondary solar resources, make up most of the renewable energy available on Earth. However, only a fraction of the solar energy available can be used across a variety of natural and artificial processes, generating electricity, heating, cooking, and water desalination. Solar energy is considered a sustainable energy as it is a natural resource and one of the cleanest green energy sources that do not contribute to greenhouse gas emissions [6]. The radiation from direct and diffuse radiation is called global radiation, which is the most important factor in studying the potential of solar energy.

\section{Solar Radiation}

Solar radiation is the product of light energy from the entire sun, measured on Earth per unit area of $\mathrm{W} / \mathrm{m}^{2}$ unit received from the sun in the form of electromagnetic radiation. It is a promising source of energy due to the large amount that Earth receives daily, which is enough to support needs of the entire planet. The following are the most important types that PV system uses to generate energy:

Direct Natural Irradiance (DNI): The amount of radiation that the device gets by a surface that is perpendicular to the direct radiation from the sun.

Diffuse Horizontal Irradiance (DHI): It is the amount of radiation received per unit area of a surface that is not directly from the sun, but rather is the result of the dispersion of radiation by the fine particles present in the atmosphere and come from all directions equally.

Global Horizontal Irradiance (GHI): It is the radiation from the sum of DHI and DNI by a surface area on the Earth that is horizontal. GHI can be expressed in the equation:

$$
\mathrm{GHI}=\mathrm{DHI}+\mathrm{DNI} \cdot \cos (\mathrm{z})
$$

Where $\mathrm{z}$ is the zenith angle of the sun. Global radiation which consists of direct and diffuse radiation is considered the most important factor to investigate the potentials of solar energy in a specific location.

\section{Photovoltaic Systems}

Photovoltaic systems are techniques that work on principle of converting sunlight and 
radiation into electrical energy by solar cells that are arranged in panels directly directed to the sun's rays. Also, it is one of the most prominent sustainable green energy systems, as it contributes to reducing the use of fossil fuels and does not cause pollution or emissions, and thus helps in obtaining a green environment, as well as being considered less maintenance. The mechanism of the photovoltaic systems is collection of solar energy from sunlight by solar cells and converted to direct current (DC). Then the (DC) moves to the inverter, which in turn converts it to alternating current (AC). Thus, this current is suitable for use in operation of electrical appliances. The most important components of the PV system are:

\subsection{The Photovoltaic Cell}

The photovoltaic cell is the most important component of the photovoltaic system, which works to convert solar energy into electrical energy by the photoelectric effect process. The amount of current produced depends on the number of units of the system, in addition to orientation, shading, sun tracking, etc. There are different types of solar cells, but they operate with the same principle, that the most important materials that go into their composition are semiconductors that in turn interact with photons coming from the sun and thus produce an electric current. The choice of the type of solar panels depends on the measurement of efficiency, price, durability and flexibility, because each type has different characteristics and specific efficiency [7]. The efficiency of solar cells refers to the energy portion in form of sunlight that can be converted by photovoltaics into electricity by solar cells. The efficiency of solar cells used in the photoelectric system depends on the quality of the panel and method of its installation, in addition to latitude and climatic conditions.

\subsection{Solar Inverter}

The inverter converts the DC output from the solar panels or storage battery into AC electricity, through which the grid is fed. There are many varieties that differ according to their efficacy. Power limit losses occur in time steps when the inverter's AC power output exceeds the board's total capacitance. In addition to losses when DC Array's voltage falls outside the minimum and maximum inverters [8].

\subsection{Other Components}

It consists of wires, control panels, fuses, junction boxes, meters, and other components.

\section{Wind Energy}

Wind energy is one of the most important and prominent sources of renewable energy. At a height of $90 \mathrm{~m}$, the mean wind speed is an indication of each location, through which it is possible to produce energy from wind turbines. It is known that average wind speed is an insufficient indicator to determine the ability of the turbines to produce energy. It is necessary to know the percentage of repetitions of wind speeds with resulting graph of wind data within a specified time period. Typically, statistical distribution function is used to describe temporal distribution of wind speed of a site. Including, it is necessary to know the symmetry of the distribution of wind speeds by shape parameter $(\mathrm{k})$ of the Weibull distribution which is an important indicator in field of wind energy study. Where the value of $(\mathrm{k})$ very close to 1 represent very unequal distributions. In addition, consideration must be given to the prevailing wind direction in the area, which is defined by drawing a chart of wind rose. The most important details related to the wind power supplier are touched upon.

\subsection{Wind Speed Extrapolation For Different Heights}

Wind speed and direction values are known to be variable, as they are influenced by several factors. Most of these factors are in the boundary layer, which is defined as the near-surface layer that extends to a height of approximately 1000 meters or more, and which response to surface changes of earth and effects of terrain, heat transfer and evaporation. This layer has a major role in changing wind direction and speed. The wind speed is variable and increases with height, and since data available in the meteorology stations are at the standard height $10 \mathrm{~m}$ and sometimes they are at a height of $50 \mathrm{~m}$ and since the turbines that generate energy 
from the wind have different heights exceeding $10 \mathrm{~m}$ so it is necessary to use an equation through which to estimate Wind speed at various altitudes [9]. The wind changes exponentially with the height. The law of the logarithmic equation is used to know the speed of the wind at different heights and can be expressed in the equation [10]:

$$
v_{2}\left(z_{2}\right)=v_{1}\left(z_{1}\right)\left(\frac{z_{2}}{z_{1}}\right)^{\alpha}
$$

Where $v_{1}$ and $v_{2}$ are the value of wind speeds at $z_{1}$ and $z_{2}$ successively. Whereas, $z_{1}$ represents the known altitude with the wind speed $v_{1}$, which is often the standard altitude $10 \mathrm{~m}$, also known $(\alpha)$ the surface friction coefficient, which is a function of surface roughness and stability, and has ideal values agreed upon. The best calculated value for this parameter is 0.14 and also the surface friction coefficient can be found in power law equation [11].

\subsection{Wind Farm}

A group of wind turbines in a specific location, covering an area that extends to square kilometers, and land located between the turbines can be used for agricultural or other purposes. The success of wind farm project depends on the wind resources available on site and planning of the wind farm, which includes number and distribution of turbines, in addition to type of turbines chosen. When $\mathrm{D}$ is the diameter of the rotor, the distance between each turbine in the direction facing the prevailing wind ranges between $6 \mathrm{D}-3 \mathrm{D}$, and the distance perpendicular to the direction of the prevailing wind ranges between 6D-3D. Therefore, attention should be paid to wind farm planning, as it reduces turbulence, increases energy production and turbine life, and reduces the burden that affects the structure of the turbines [12].

\section{Study Area}

Anah city is located in western Iraq in Al-Anbar Governorate on the banks of Tigris River near Haditha dam. It has the advantage of having fertile land for agriculture, water and renewable energy resources and temperate climate, in addition to the percentage of pollutants in it is very low. It also has green spaces that contribute to agricultural investments and the development of the economy of the city, in addition to entertaining the residents and contributing to decreases the temperature. Anah has an Annual Sum of DNI which equals 5.4 $\mathrm{kWh} / \mathrm{m}^{2}$ per day, and average Daily GHI which equals $1972 \mathrm{kWh} / \mathrm{m}^{2}$, and average wind speed with height $90 \mathrm{~m}$ equals $6.7 \mathrm{~m} / \mathrm{s}$. Anah site is considered one of the promising areas to invest in renewable energy represented by solar and wind energy in Iraq. The location can be shown on the map of Iraq in Figure 2. 


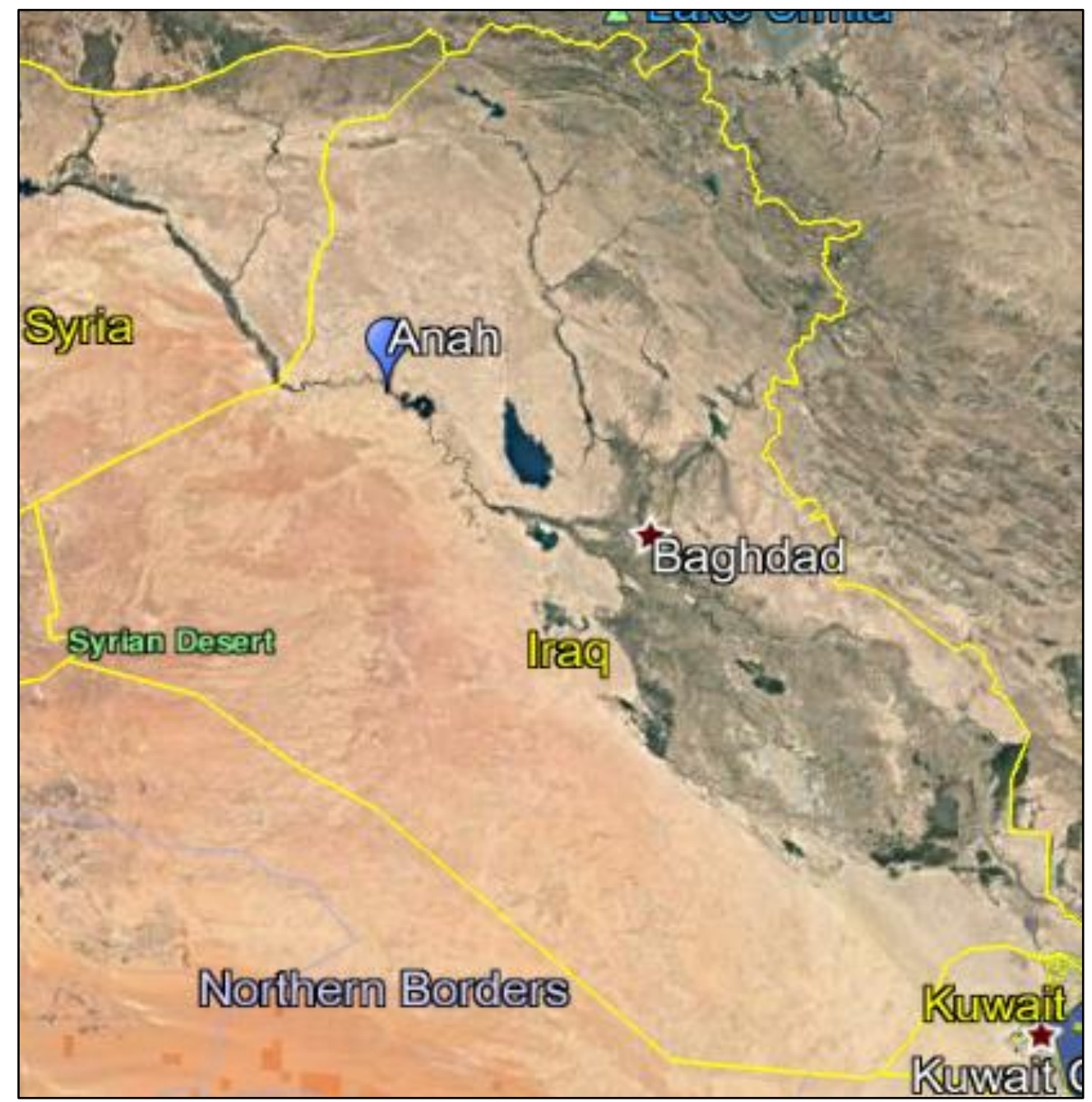

Figure 2-Anah city as shown on the map of Iraq.

The most prominent statistical characteristics of the region can be summarized in Table 1.

Table 1-Statistical characteristics of study area

\begin{tabular}{cc}
\hline Parameters & Value \\
\hline${\text { Latitude }\left({ }^{\circ}\right)}^{\circ}$ & 34.39 \\
Longitude $\left(^{\circ}\right)$ & 41.97 \\
Elevation $(\mathrm{m})$ & 211 \\
Temperature $\left(C^{o}\right)$ & 21.15 \\
Relative humidity & 39.1 \\
Average Daily GHI & 5.4 \\
$\quad\left(\mathrm{kWh} / \mathrm{m}^{2}\right.$ day) & 1972 \\
Annual Sum of DNI & \\
$\quad\left(\mathrm{kWh} / \mathrm{m}^{2}\right)$ & 4.14 \\
Wind speed (m/s) with & \\
height $10 \mathrm{~m}$ & 6.7 \\
Wind speed (m/s) with & 2.17 \\
height $90 \mathrm{~m}$ & 2.03 \\
Weibull Shape Factor $k$ & \\
Standard deviation &
\end{tabular}




\section{Results and discussion}

\subsection{Planning of Sustainable City}

The sustainable city structure of Anah will be designed in a form of a circular section. The population of the city will be 30000 depending on the population of the Anah city, according to statistics from the Ministry of Planning in 2013. The AutoCAD program was used to design the circular city shown in Figure3.

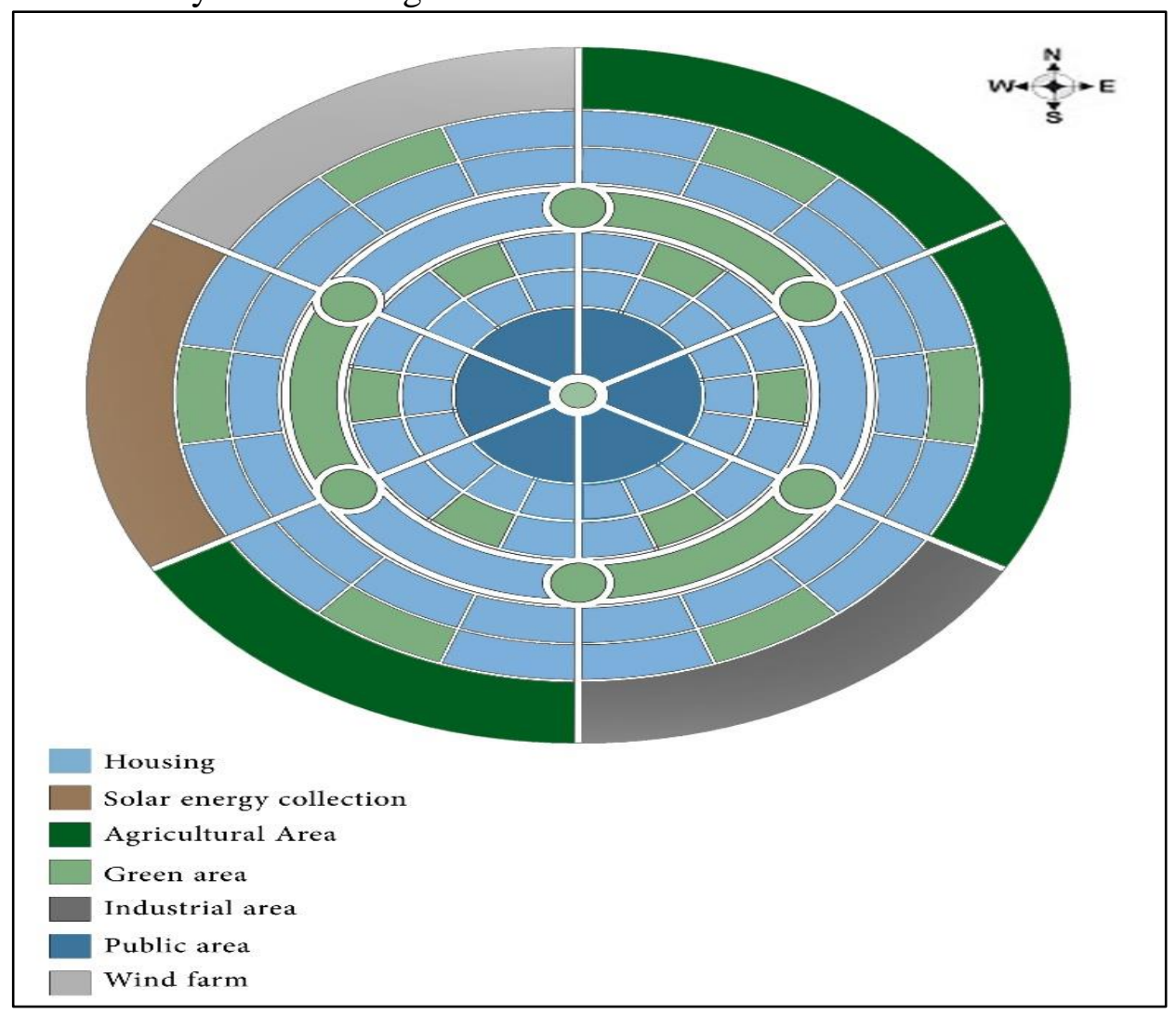

Figure 3-Anah waterwheel sustainable city plan.

The circular design of the city has been relied upon based on the shape of the waterwheel in the city of Anah. As for the architectural aspect, there are several factors, the most prominent of which is the proximity of the residential sectors to the center, in addition to proximity of transportation and possibility of reaching on foot or using bicycles. The city is divided into seven main parts distributed in different proportions, which is housing area that has obtained $27.54 \%$ of the total area of the city, with a total area of $2751318 \mathrm{~m}^{2}$ divided into 7500 apartments, the area of one apartment is $200 \mathrm{~m}^{2}$ contains four people, and distributed to 500 apartments for one sector thus becomes 15 sectors in the city. This area also includes accessories for the residential sector, which includes transportation routes and home gardens. The green areas obtained $13.69 \%$ of the total area of the city, distributed among the residential sectors. The purpose of distributing green areas among residential sectors is to entertain residents and increase air quality by emitting oxygen from plants in addition to reducing the temperature and air conditioning within the city because it limits the presence of greenhouse gases.

While the agricultural areas obtained $14.4 \%$ of the total area of the city, distributed on the city's periphery to invest the surrounding lands and provide agricultural crops to the city, and this supports the city economically. In addition to the purpose of this distribution, which is considered as a green belt surrounding the city, which in turn reduces the entry of pollutants and dust into the city. 
The public areas also obtained $9.28 \%$ of the total area of the city, which was placed in the city center, to facilitate access by the residents. The general area includes educational institutions, hospital, markets, the mosque, a public library and a security center and a civil defense center in addition to the control center, city affairs administration.

The wind farm got $9.19 \%$ of the total area of the city, designed northwest of the city to counter the prevailing winds, which are known as northwestern winds before passing through the city. This is to reduce turbulence in the speed of the winds that form after the passage of winds over the city due to the irregularity of the surface consisting of buildings and trees. Details of the wind farm will be explained later.

The industrial area also obtained a percentage of $8.94 \%$ of the total area of the city, containing the most important local industrial centers, including recycling centers. It is designed in the southeast of the city to reduce emissions from industrial centers that are heading towards prevailing winds away from the city.

The solar energy collection area also obtained $16.94 \%$ of the total area of the city, which contains the components of the solar system and a large number of solar panels. This area includes $60 \%$ of the roofs of buildings.

The urban housing standards for the year 2010 of the Iraqi Ministry of Construction and Housing were used to distribute the percentage to the regions. The area and proportion of each region in the city can be summarized in Table 2.

Table 2-The area and proportion of each region in the city

$\begin{array}{ccc}\text { Region } & \text { Area }\left(\mathbf{m}^{\mathbf{2}}\right) & \text { Percentage }(\boldsymbol{\%}) \\ \text { Housing } & 2,751,318 & 27.54 \\ \text { Solar Energy Collection } & 1,693,235 & 16.94 \\ \text { Agricultural area } & 1,438,615 & 14.4 \\ \text { Green Area } & 1,367,723 & 13.69 \\ \text { Industrial Area } & 893,310 & 8.94 \\ \text { Public Area } & 927,514 & 9.28 \\ \text { Wind Farm } & 918,472 & 9.19 \\ \text { Total Area } & \mathbf{9 , 9 9 0 , 1 8 7} & \mathbf{1 0 0}\end{array}$

\subsection{Energy System in Sustainable City}

Energy will be provided in the sustainable city of Anah waterwheel by relying on $30 \%$ of the energy from renewable energy sources that include wind and solar energy, while the national grid will provide the other $70 \%$ of the city's total electricity. For residential homes, $5 \mathrm{~kW}$ will be assumed for every household in the city, $30 \%$ of which will be saved by renewable energy. As for industrial areas, they will depend on the national network. The annual total energy from wind and solar resources were calculated using SAM program.

\subsubsection{Wind Farm}

The wind farm was designed and directed in the northwestern part of the city as shown in Figure 3. Windographer software was also used to draw a wind rose diagram in which the direction of the prevailing winds is determined, through which it was found that about $60 \%$ of the total prevailing winds were in the northwest direction in the site, a wind rose diagram can be shown in Figure 4. 


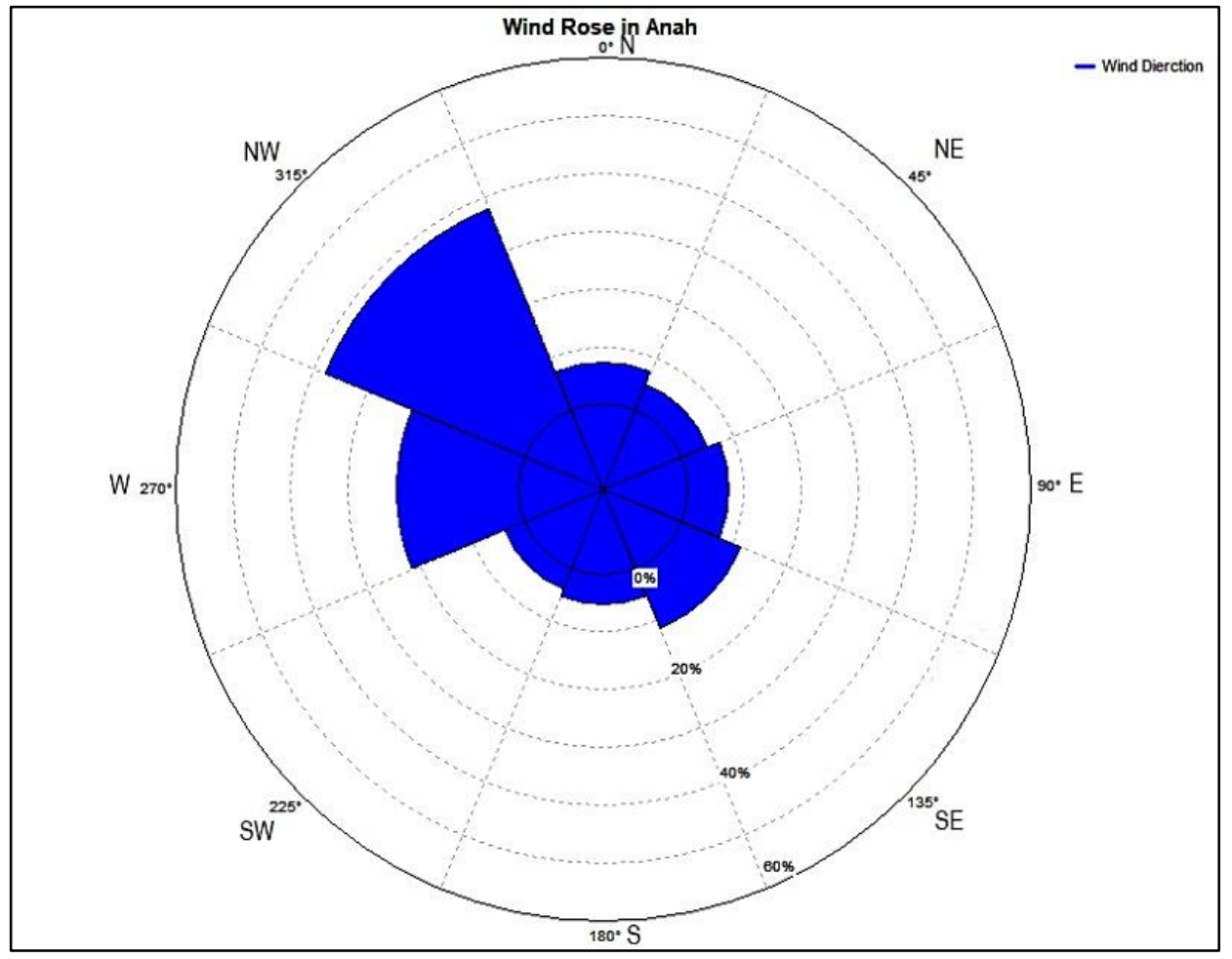

Figure 4-Wind rose for the study area.

The wind farm contains 15 general electric 1.5xle turbines with a production power of about 1.5 MW. These turbines are distributed over three rows and five columns, rows will be oriented $18^{\circ}$ angle west of north.

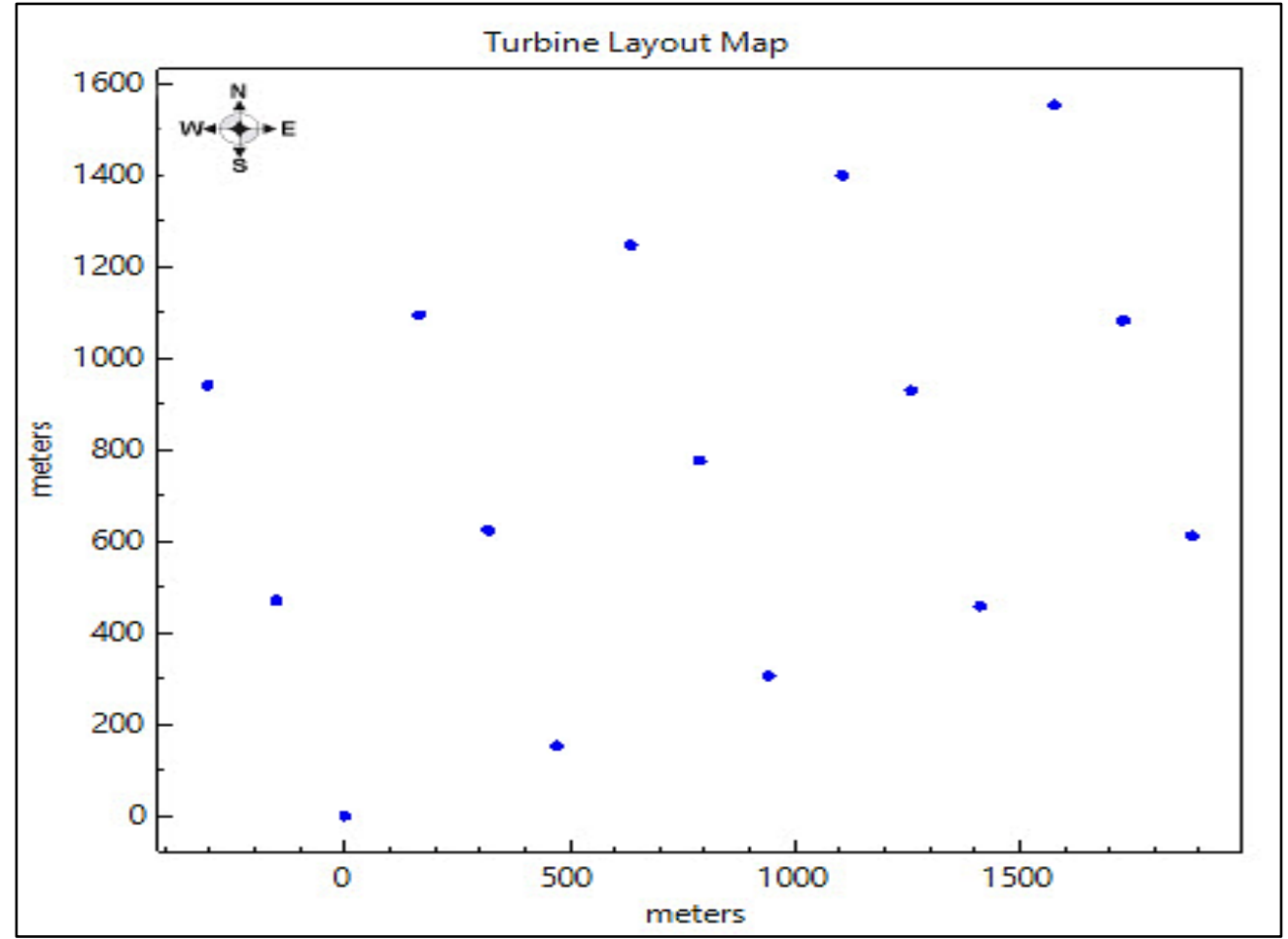

Figure 5-Wind farm scheme in the study area.

Which includes 15 turbines distributed in 5 rows and three columns, where the distance between each turbine in the wind farm that gives the best energy results is $6 \mathrm{D}$ between the row and the column. The scheme of the wind farm that was designed for the city can be 
illustrated in Figure 5. After selecting the site and designing the farm, SAM program was used to calculate the amount of energy produced from the wind farm. The average monthly energy production was calculated from the wind farm as shown in Figure 6.

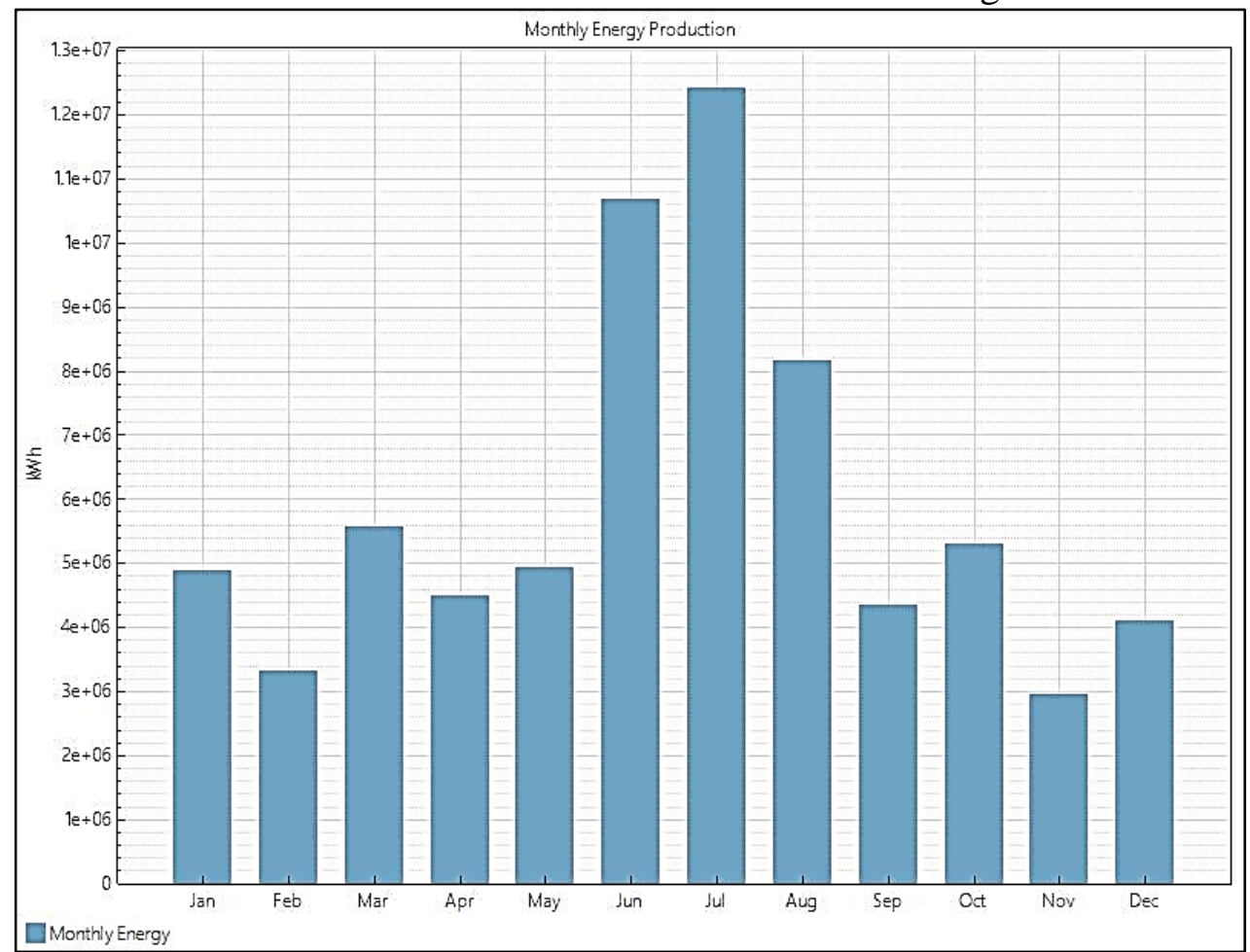

Figure 6- Average monthly production of energy generated from wind farm.

The highest value of energy production from the wind farm was recorded in the summer months, and the reason is due to the high temperatures in the summer season. It is known that the city of Anah is adjacent to the Euphrates River, which causes a temperature difference between the land and water that causes movement activity Wind and thus increases production in summer.

The net annual total energy generated from the wind farm is about $71080608 \mathrm{kWh}$ and the capacity factor ratio is $36.1 \%$.

\subsubsection{Photovoltaic System}

For solar energy, each house will be assumed containing 20 RSM60-6-260P modules with a production capacity of $300 \mathrm{~W}$ arranged in the form of five rows and four columns occupying an area of $40 \mathrm{~m}^{2}$, connected to two inverter type SAM America SB3000TL-US-22 (208V) with a power conversion of $3000 \mathrm{Wac}$ and $3194 \mathrm{Wdc}$ each one inverter. Also, the solar tilt angle is $29^{\circ}$, the solar azimuth angle is $135^{\circ}$, and the total loss in production and conversion is $10 \%$. The annual output for each system was obtained $12527 \mathrm{kWh}$ and capacity factor $23.8 \%$. Figure 7, shows the monthly energy production.

The results show that the highest value of energy production in the summer months is about $1350 \mathrm{kWh}$, due to the increase in daylight hours, which reach about 10 hours, and thus the intensity of direct and natural solar radiation increases, in addition to clear skies on most summer days. Contrary to the winter months, in which the daylight hours are short and the intensity of solar radiation is less than in the Summer months due to the presence of clouds in most of Winter. 


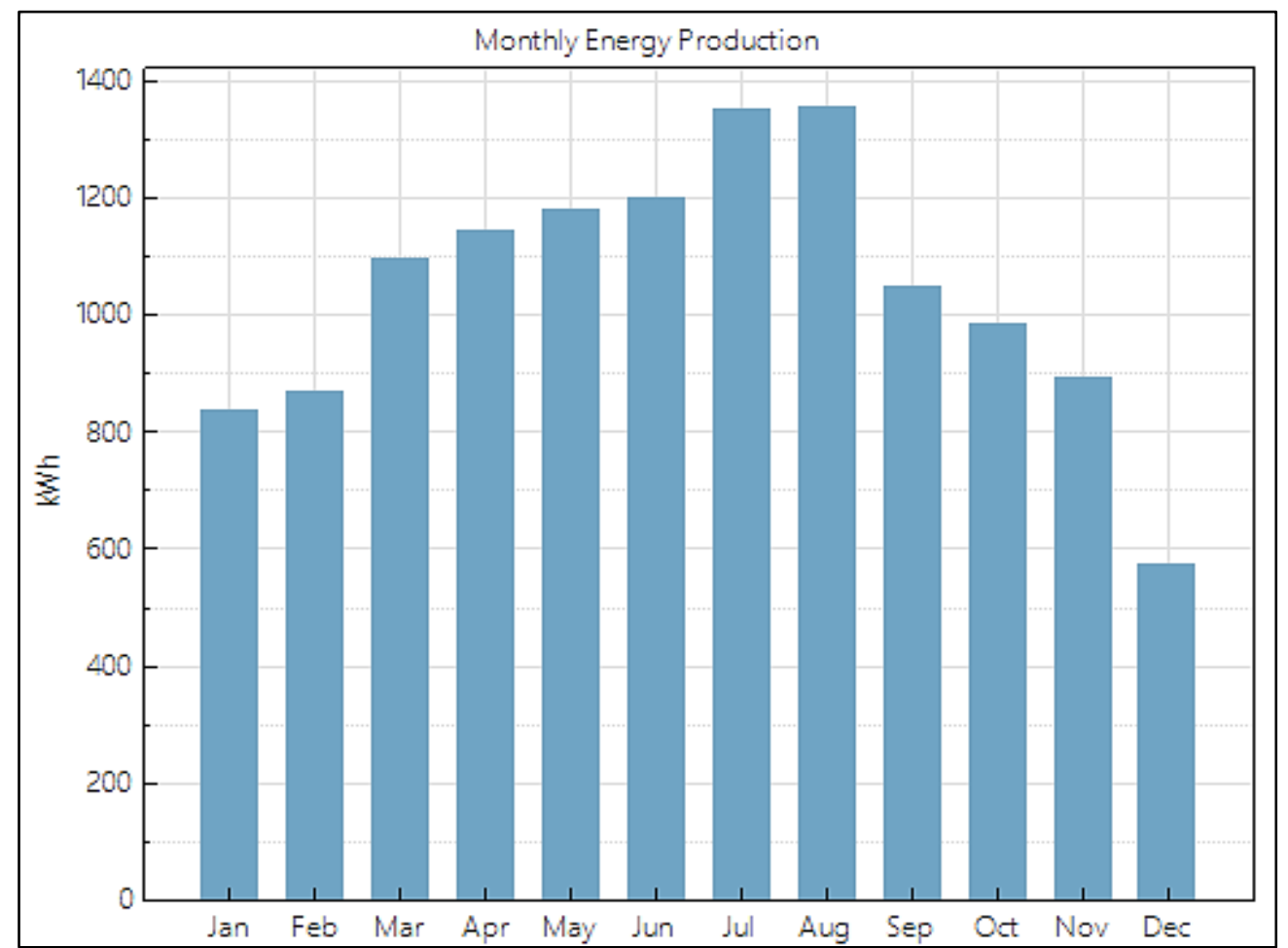

Figure 7-Monthly energy production for PV system for each house.

\section{Conclusions}

The importance of the circular design of the city lies in proximity of residential areas to the center, and use of walking or bicycle use to reduce the means of transportation that contribute to emission of pollutants. Also, embodiment of circular shape of the water wheel in Anah city. In terms of renewable energy, the wind farm is designed consisting of 15 turbines, with three rows and five columns. Using SAM program, it was found that the best orientation for the rows is at an angle of 18 degrees west from the north, and the best distance between the turbines within the wind farm is $6 \mathrm{D}$ between the row and the column in order to exploit the prevailing winds at the site, which recorded about $60 \%$ of the total wind and thus obtain the highest value of the energy produced in this Site.

Also, designing 20 solar panels with a power of 300 watts per home is sufficient to save $30 \%$ of the total energy used in the home.

In the field of solar energy, we conclude that the best tilt angle is $29^{\circ}$, while the solar azimuth angle is $135^{\circ}$, through which highest energy production is obtained by solar panels at the study site. The highest value of solar energy production in the Summer months was about $1350 \mathrm{kWh}$. This is due to the increase in daylight hours, which reach about 10 hours, which increases the amount of direct and natural solar radiation, in addition to clear skies on most of the Summer days.

\section{REFERENCES}

[1] H. H. Al-Kayiem and S. T. Mohammad, "Potential of Renewable Energy Resources with An Emphasis on Solar Power in Iraq: An Outlook", Resources, vol. 8, p. 42, 2019.

[2] L. Seeliger and I. Turok, "Towards Sustainable Cities: Extending Resilience with Insights from Vulnerability and Transition Theory", Sustainability, vol. 5, pp. 2108-2128, 2013.

[3] D. Brodowicz, P. Pospieszny, and Z. Grzymala, "Eco-cities", https://depot. ceon.pl /handle/123456789/9224, 2015.

[4] C. Macharis and B. Kin, "The 4 A's of Sustainable City Distribution: Innovative Solutions and Challenges Ahead", International Journal of Sustainable Transportation, vol. 11, no. 2, pp. 59$71,2017$. 
[5] A. Alkhalidi, L. Qoaider, A. Khashman, A. R. Al-Alami, S. Jiryes, "Energy and Water as Indicators for Sustainable City Site Selection and Design in Jordan Using Smart Grid", Sustain. Cities Soc., vol. 37, p.p. 125-132, 2017.

[6] K. H. Solangi, M. R. Islam, R. Saidur, N. A. Rahim, and H. Fayaz, "A Review on Global Solar Energy Policy”, Renew. Sustain. Energy Rev., vol. 15, no. 4, pp. 2149-2163, 2011.

[7] A. Ketsetzi and M. M. Capraro, "Renewable Energy Source, A Companion to Interdiscip. Stem Proj. Learn. Educ. by Educ", Second Ed., no. 801, pp. 145-153, 2016.

[8] H. K. V Lotsch et al., Optical Sciences, 2007.

[9] Y.-H. Wan, E. Ela, and K. Orwig, "Development of An Equivalent Wind Plant Power-Curve", National Renewable Energy Lab. (NREL), Golden, CO (United States), 2010.

[10] I. Troen, "A High-Resolution Spectral Model for Flow in Complex Terrain In 9th Symposium on Turbulence and Diffusion”, pp. 417-420, 1990.

[11] R. P. Mukund, "Wind and Solar Power Systems", ed: CRC press, 1999.

[12] B. A. Mohammed, "Effect of Turbulence Intensity on Wind Turbine Performance, PhD. Thesis, Mustansiriyah University, College of Science, Department of Atmospheric Science, 2015. 